\title{
Dynamic response analysis of the integrated station-bridge elevated station under the pile-soil interaction
}

\author{
Shuqi Zhang ${ }^{1 *}$, Jin $\mathrm{Li}^{1}$, Jingyuan $\mathrm{Li}^{1}$ and Jiaolei Zhang ${ }^{1}$ \\ ${ }^{1}$ civil engineering, Xi'an University of Architecture and Technology, Xi 'an, shanxi, 710055, China
}

\begin{abstract}
In order to study the dynamic response of the integrated station-bridge structure under the pile-soil interaction, a model was established by finite element software for dynamic analysis. According to a practical project, two mechanical models are established: one is the pile-soil interaction model, the other is the rigid foundation model. The dynamic responses of the two models were analyzed respectively, and then the results were compared. The results show that: the structure with pile-soil interaction has a longer period and higher flexibility; Under the action of frequently occurred earthquakes, the maximum displacement of the structure with pile-soil interaction increases and the base shear decreases; Under the action of seldomly occurred earthquakes, the structural displacement and base shear under the pile-soil interaction become larger, and the transverse displacement is more affected than the longitudinal displacement. It is concluded that: the assumption of rigid foundation makes the result more conservative, and the influence of pile-soil interaction cannot be ignored in seismic response analysis.
\end{abstract}

\section{Introduction}

Elevated station buildings can generally be divided into two categories: "integrated station-bridge structure "and "detached station-bridge structure"[1,2].The separation of other major structures bearing non-vehicle loads and the crane girder structures bearing vehicle loads is "detached station-bridge structure"; otherwise, it is "integrated station-bridge structure". The integrated station-bridge structure is composed of building units and bridge units. It not only has the characteristics of building and bridge structures, but also makes the building and bridge structures form a whole to play a role $[3,4]$.

The research on the structure at home and abroad is still in the preliminary stage, so no effective theory has been formed, and the earthquake resistant design code has not been formulated. Therefore, the earthquake resistant design code for buildings and bridges is usually used to design detached station-bridge structures. The code refers to Code for seismic design of buildings [5] and Code for seismic design of railway engineerings [6].

The integrated station-bridge structure is a new structure system which has emerged in recent years. Its stress characteristic is complex, the earthquake action is difficult to analyze. In order to study its dynamic response, we usually combine the building and the bridge into a structure[7] and then analyze the structure. In order to verify the earthquake resistance of the structure, the structural elastic-plastic [8] time history analysis of the structure under the action of megaseism should also be carried out. In addition, the foundation type has a non-negligible influence on the dynamic response and stress characteristics of the structure, and the appropriate foundation type should be fully considered in the design $[9,10]$. When building a model, we usually use only fixed constraints to simplify the calculation. However, in the actual situation, dynamic load deforms the foundation, which affects the dynamic response and stress characteristics of the superstructure [11]. Therefore, in order to accord with the actual situation, we should establish the foundation of pile- soil interaction.

In order to study the dynamic response of the integrated station-bridge structure based on pile-soil interaction, this paper takes the actual engineering of xi 'an metro line 5 as an example and establishes models through finite element software .The "m "method [12] was used to simulate the pile-soil interaction. The dynamic response and stress characteristics of structures under earthquake action are analyzed, and the results are compared to obtain the effect of pile-soil interaction on the structure.

\section{Structural modal analysis}

\subsection{Finite element model}

Finite element software MIDAS/GEN was used to establish the three-dimensional space finite element model. The beam element was used for girders, columns, foundations and piles, and the shell element was used for floor slabs. Fixed connection of column bottom and ground to simulate rigid foundation (Figure1). The pile element is divided appropriately, and elastomeric bearing is added according to the stiffness coefficient of soil 
spring to simulate the pile-soil interaction (Figure2).Floor elements, beam elements and column elements are Concurrent units. When calculating the dynamic response, this structure only considers the

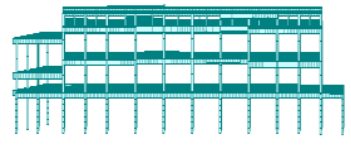

Figure1.Rigid foundation model

\subsection{Structural modal analysis}

Modal analysis is the main method to study the dynamic characteristics of structures [13]. Therefore, the calculation of the self-vibration characteristics is a prerequisite for the analysis of the dynamic response. Since the rigidity and mass of the structure vary greatly in the longitudinal and the transverse direction, there are obvious space effect, and the dynamic response of the structure is relatively concentrated, the subspace iteration method is suitable for solving the model. longitudinal-horizontal earthquake action and the transverse-horizontal earthquake action, so only considers the horizontal pile-soil interaction.

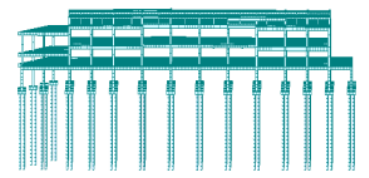

Figure2.Pile-soil interaction model

The pile-soil interaction model and the rigid foundation model are analyzed. The periodic changes of the first 15 modal order is shown in Figure3.According to the results, the natural vibration period of the pile-soil interaction model is longer, and the increase of the first period and the fifth period is the largest. The first period increased from $0.637 \mathrm{~s}$ to $0.961 \mathrm{~s}$, an increase of about $51 \%$. As the order increases, the two curves converge. It can be seen that the rigidity becomes smaller and the period becomes longer due to the pile-soil interaction.

Table1.The first four modes

\begin{tabular}{ccc}
\hline The modal & Rigid foundation & piles -soil interaction \\
\hline 1 & transversely translational & transversely translational \\
2 & longitudinally translational & longitudinally translational \\
3 & torsional deformation & torsional deformation \\
4 & torsional deformation & torsional deformation \\
\hline
\end{tabular}

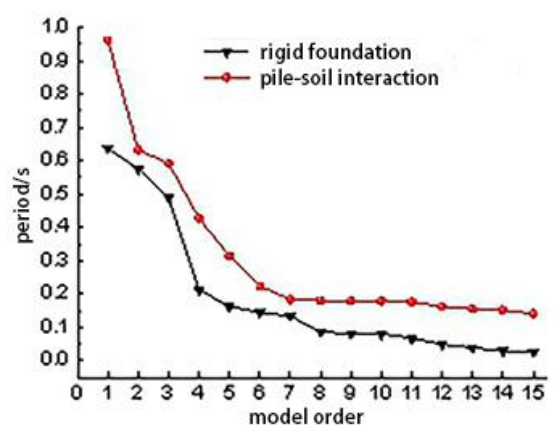

Figure3. Periodic changes of the first 15 modal order numbers

In addition, the first four modal order of the two models change the same: the the first-order mode is mainly transversely translational; the second-order mode is mainly longitudinally translational; the third-order mode and fourth-order mode are mainly torsional deformation. Thus, the longitudinal rigidity of the structure is greater than the transverse and the low order modes are basically the same, regardless of the pile-soil interaction. The results are shown in Table1.

\section{Dynamic response analysis of structures under the frequently occurred earthquake action}

\subsection{Response spectrum analysis of structures under the frequently occurred earthquake action}

In the case of frequently occurred earthquake, the maximum seismic influence coefficient is 0.16 , the eigenperiod is 0.40 , and the damping ratio is 0.05 . The structure model adopts CQC method to modal combination and obtain the dynamic response of the structure under the bidirectional seismic action. The results of two kinds of foundation assumptions are compared to obtain the effect of pile-soil interaction on the structure. The calculated results are shown in the following table

Table2. Longitudinal story drift and interlaminar displacement angle

\begin{tabular}{ccccc}
\hline Floor & \multicolumn{2}{c}{ Rigid foundation model } & \multicolumn{2}{c}{ Pile-soil interaction model } \\
Story drift $/ \mathrm{m}$ & $\begin{array}{c}\text { Interlaminar } \\
\text { displacement angle }\end{array}$ & Story drift $/ \mathrm{m}$ & $\begin{array}{c}\text { Interlaminar } \\
\text { displacement angle }\end{array}$ \\
\hline 1 & 0.0004 & $1 / 16625$ & 0.0014 & $1 / 4714$ \\
\hline
\end{tabular}




\begin{tabular}{ccccc}
\hline 2 & 0.0061 & $1 / 848$ & 0.0060 & $1 / 926$ \\
3 & 0.0058 & $1 / 911$ & 0.0058 & $1 / 908$ \\
4 & 0.0007 & $1 / 2883$ & 0.0007 & $1 / 2839$ \\
\hline
\end{tabular}

Table3. Transverse story drift and interlaminar displacement angle

\begin{tabular}{|c|c|c|c|c|}
\hline \multirow[b]{2}{*}{ Floor } & \multicolumn{2}{|c|}{ Rigid foundation model } & \multicolumn{2}{|c|}{ Pile-soil interaction model } \\
\hline & Story drift/m & $\begin{array}{c}\text { Interlaminar } \\
\text { displacement angle }\end{array}$ & Story drift/m & $\begin{array}{c}\text { Interlaminar } \\
\text { displacement angle }\end{array}$ \\
\hline 1 & 0.0024 & $1 / 2698$ & 0.0039 & $1 / 1673$ \\
\hline 2 & 0.0050 & $1 / 1037$ & 0.0044 & $1 / 1175$ \\
\hline 3 & 0.0043 & $1 / 1235$ & 0.0035 & $1 / 1512$ \\
\hline 4 & 0.007 & $1 / 2876$ & 0.0006 & $1 / 3446$ \\
\hline
\end{tabular}

It can be seen from Table2 and Table3 that: the maximum story drift of the two models under the bidirectional seismic action occurs in the second layer; in the model of pile-soil interaction, only the story drift of the second layer is smaller than that of the rigid foundation model, while the rest layer is larger than that of the rigid foundation model; the maximum interlaminar displacement angle of the rigid foundation model is
$1 / 848$ and $1 / 1037$ in both the longitudinal and transverse directions, which is less than 1/550 in the earthquake resistant design code; the maximum interlaminar displacement angle of the pile-soil interaction model is $1 / 848$ and 1/1037 in both the longitudinal and transverse directions, which was also less than $1 / 550$ in the earthquake resistant design code. Both models conform to the specification.

Table4. base shear under the bidirectional seismic action

\begin{tabular}{cccc}
\hline $\begin{array}{c}\text { Earthquake } \\
\text { action }\end{array}$ & $\begin{array}{c}\text { Direction of } \\
\text { structure }\end{array}$ & Rigid foundation model $/ \mathrm{kN}$ & Pile-soil interaction model $/ \mathrm{kN}$ \\
\hline $\begin{array}{c}\text { Longitudinal } \\
\text { earthquake }\end{array}$ & Longitudinal & $4.28 \mathrm{e}+04$ & $3.95 \mathrm{e}+04$ \\
action & Transverse & $4.27 \mathrm{e}+03$ & $3.64 \mathrm{e}+03$ \\
$\begin{array}{c}\text { Transverse } \\
\text { earthquake }\end{array}$ & Longitudinal & $4.59 \mathrm{e}+03$ & $3.66 \mathrm{e}+03$ \\
action & Transverse & $4.12 \mathrm{e}+04$ & $3.47 \mathrm{e}+04$ \\
\hline
\end{tabular}

Table4 shows that: in the model of pile-soil interaction, the base shear decreases under the response spectrum, and the decrease range is less than $10 \%$; the results of the rigid foundation model are conservative under the frequently occurred earthquake.

\subsection{Time history analysis of structures under the frequently occurred earthquake action}

\subsubsection{Selecting seismic waves}

According to the Code for seismic design of buildings, under the frequently occurred earthquake, especially irregular buildings should undergo not only response spectrum analysis but also time history analysis. In time history analysis, natural seismic waves and artificial seismic waves should be selected as input waves, and the number of natural seismic waves should not be less than $2 / 3$ of the total number. The characteristics of seismic waves should be consistent with the construction site conditions and meet the requirements of the site environment, seismic precautionary intensity and duration. ASCE [14] stipulated that the selection of seismic waves should take into account such factors as earthquake magnitude, epicentral distance and hypocentral distance. According to the site conditions of the building and the wave selection elements provided by the Pacific seismic research center (Table5), a total of three seismic waves were selected as input waves: two natural seismic waves (GM1, GM2) and one artificial wave (GM3), and artificial wave is obtained by software SIMQKE_GR and Spectrum_Chinese.The information of seismic wave GM1 and GM2 is shown in Table6.

Table5.Selected seismic wave elements

\begin{tabular}{cc}
\hline Elements & Scope \\
\hline Earthquake & \\
magnitude & $5 \sim 9$ \\
Epicentral & $0 \sim 500$ \\
distance $/ \mathrm{km}$ & $0 \sim 500$ \\
Hypocentral & $250 \sim 500$ \\
distance $/ \mathrm{km}$ &
\end{tabular}

Instructions: $\mathrm{Xi}$ 'an is located at the site of the near moderate earthquake; The equivalent velocity of waves at $30 \mathrm{~m}$ above the surface. 
Table6.Natural wave information

\begin{tabular}{|c|c|c|c|c|c|c|}
\hline Number & Name & Time & Record the platform & $\begin{array}{l}\text { Earthquake } \\
\text { magnitude }\end{array}$ & $\begin{array}{c}\text { Epicentral } \\
\text { distance } / \mathrm{km}\end{array}$ & $\mathrm{Vs} 30 / \mathrm{m} / \mathrm{s}$ \\
\hline GM1 & Parkfield & 1966 & $\begin{array}{c}\text { Cholame - Shandon Array } \\
\# 12\end{array}$ & 6.19 & 17.64 & 408.93 \\
\hline GM2 & San Fernando & 1971 & 2516 Via Tejon PV & 6.61 & 55.2 & 316.46 \\
\hline
\end{tabular}

\subsubsection{The result of elastic time history analysis}

In orderto obtain the base shear of the structure, the model was calculated by the mode superposition response spectrum method and time history analysis. The response spectrum result for the rigid foundation model is codenamed CQC. The base shear results are shown in Table7.The ratio of time history analysis results to response spectrum analysis results is shown in Table8.

Table7.Base shear under different seismic waves

\begin{tabular}{cccccc}
\hline Earthquake action & Direction of structure & CQC $/ \mathrm{kN}$ & GM1/kN & GM2/kN & GM3/kN \\
\hline Longitudinal & Longitudinal & $4.28 \mathrm{e}+04$ & $4.07 \mathrm{e}+04$ & $4.87 \mathrm{e}+04$ & $3.81 \mathrm{e}+04$ \\
earthquake & Transverse & $4.27 \mathrm{e}+03$ & $3.36 \mathrm{e}+03$ & $4.43+03$ & $3.54+03$ \\
Transverse & Longitudinal & $4.59 \mathrm{e}+03$ & $3.33 \mathrm{e}+03$ & $4.72 \mathrm{e}+03$ & $3.75 \mathrm{e}+03$ \\
earthquake & Transverse & $4.12 \mathrm{e}+04$ & $4.26 \mathrm{e}+04$ & $4.49 \mathrm{e}+04$ & $4.01 \mathrm{e}+04$ \\
\hline
\end{tabular}

Table8.Result ratio of base shear

\begin{tabular}{ccccc}
\hline Earthquake action & Direction of structure & GM1/CQC & GM1/CQC & GM1/CQC \\
\hline \multirow{2}{*}{ Longitudinal action } & Longitudinal & 0.95 & 1.13 & 0.89 \\
& Transverse & 0.78 & 1.03 & 0.82 \\
\multirow{2}{*}{ Transverse earthquake } & Longitudinal & 0.72 & 1.02 & 0.81 \\
& Transverse & 1.03 & 1.13 & 0.94 \\
\hline
\end{tabular}

The results show that: $80 \%$ the base shear of the structure calculated by each seismic wave is not less than $65 \%$ of the result calculated by the mode-superposition response spectrum method, and the average base shear of the structure calculated by the three seismic waves is not less than $80 \%$ of the result calculated by themode-superposition response spectrum method.It can be proved that the selected seismic waves conform to the specification.

\section{$4 \quad$ Elastic-plastic time history analysis of structures under the seldomly occurred earthquake action}

Under the seldomly occurred earthquake action, some structures have entered the plastic stage, and the internal forces have been redistributed due to the yielding of some units. Therefore, according to the elastic time history analysis, the obtained results can no longer truly reflect the dynamic response under the seldomly occurred earthquake action. Elastic-plastic time history analysis adopts the direct integration method [15] and can accurately simulate the whole process of the dynamic response and detect the weak parts of the structure under the earthquake action, which is an effective supplement to the seismic calculation method.

\subsection{Selecting seismic waves}

The rules for selecting seldomly occurred earthquake waves are the same as those for selecting frequently occurred earthquake waves. In the case of seldomly occurred earthquakes, the maximum seismic influence coefficient is 0.12 . In this paper, two natural waves( RSN9, RSN68)and one artificial wave are selected as input seismic waves for time history analysis. The information of seismic wave RSN9 and RSN68 is shown in Table9.

Table9.Natural wave information

\begin{tabular}{ccccccc}
\hline Number & Name & Time & Record the platform & $\begin{array}{c}\text { Earthquake } \\
\text { magnitude }\end{array}$ & $\begin{array}{c}\text { Epicentral } \\
\text { distance } / \mathrm{km}\end{array}$ & Vs30/m/s \\
\hline RSN9 & Borrego & 1942 & $\begin{array}{c}\text { El Centro Array \#9 } \\
\text { San }\end{array}$ & 6.5 & 56.88 & 213.44 \\
RSN68 & $\begin{array}{c}\text { Fernando } \\
\text { LA - Hollywood Stor }\end{array}$ & FF & 6.61 & 22.77 & 316.46 \\
\hline
\end{tabular}




\subsection{Elastic-plastic time history analysis under the seldomly occurred earthquake action}

Three selected seldomly occurred earthquake waves are input to analyze the elastic-plastic time history of the structure. By selecting a point on the top of the structure as the displacement detection point, the displacement

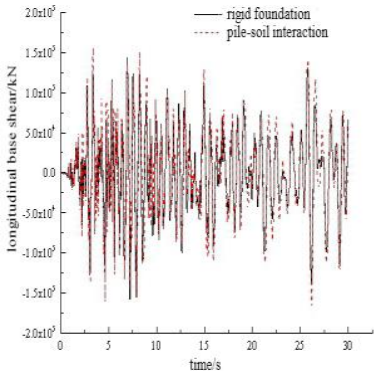

(a)

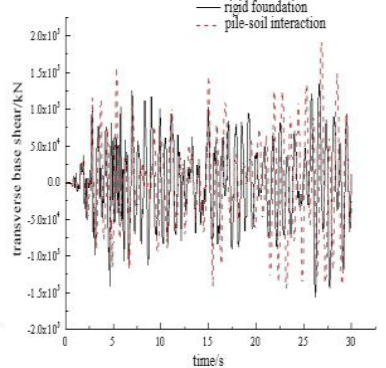

(b)

time history curve of this point can be obtained. we can analyze the time history curves of rigid foundation model and pile-soil interaction model, and summarize the rule of influence of pile-soil interaction on structure.

1.stress and displacement analysis under the seismic wave RSN9 action

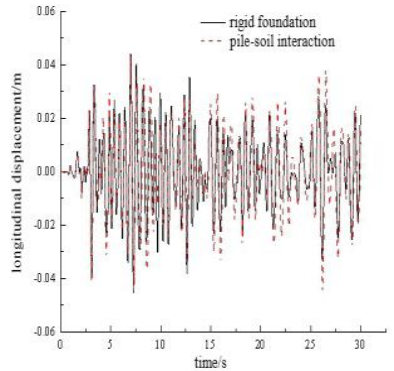

(c)

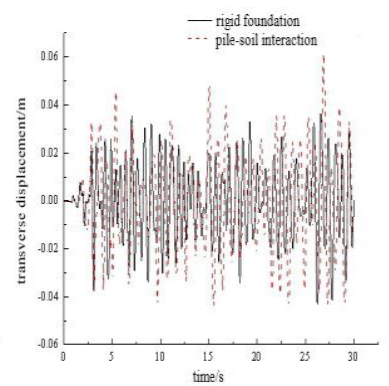

(d)

Figure4.The time history curves of the base shear and the displacement

As shown in Figure4, (a) and (b) can see that the pile - soil interaction under the action of natural wave RSN9 has a magnifying effect on the base shear, with the maximum increase in the transverse by 1.5 times and the maximum increase in the longitudinal by 1.1 times. From (c) and (d), it can be seen that the pile -soil interaction under the action of seismic wave RSN9 has a magnifying effect on the structural displacement, with the maximum increase in the transverse by 1.5 times and the maximum increase in the longitudinal by 1.1 times.

2 .stress and displacement analysis under the seismic wave RSN68 action

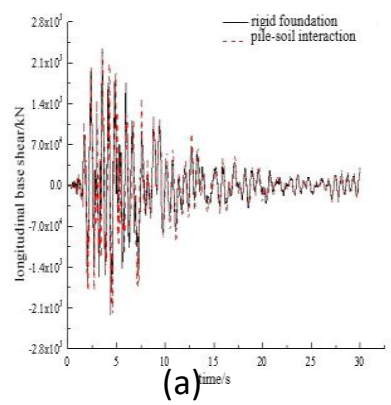

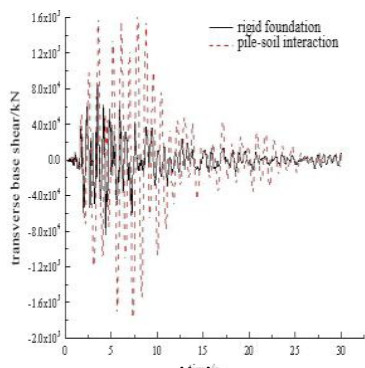

$(b)^{s}$

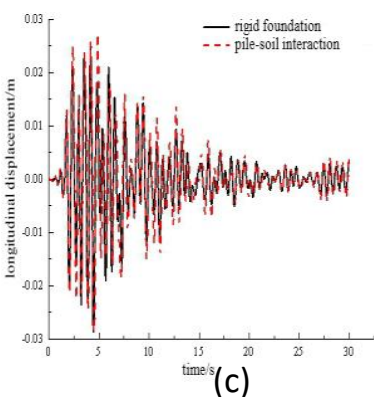

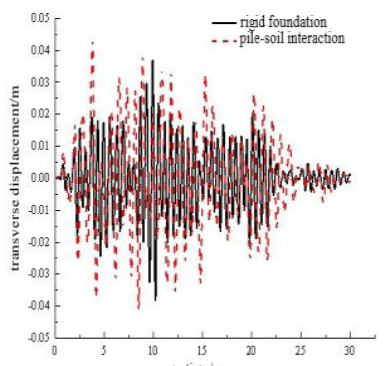

$(d)^{\prime \prime s}$

Figure5.The time history curves of the base shear and the displacement

As shown in Figure5, (a) and (b) can see that the pile -soil interaction under the action of natural wave RSN68 has a magnifying effect on the base shear, in which the transverse increases significantly, reaching 2 times. From (c) and (d), it can be seen that pile-soil interaction under the action of natural wave RNS68 has a magnifying effect on displacement, in which the transverse increases significantly, reaching 1.2 times. 3.stress and displacement analysis under the artificial seismic wave action

As shown in Figure6, (a) and (b) can see that the pile -soil interaction under the action of Artificial seismic wave has a magnifying effect on the base shear, in which the transverse increases significantly, reaching 1.8 times. From (c) and (d), it can be seen that pile-soil interaction under the action of Artificial seismic wave has a magnifying effect on displacement, in which the transverse increases significantly, reaching 1.2 times. 


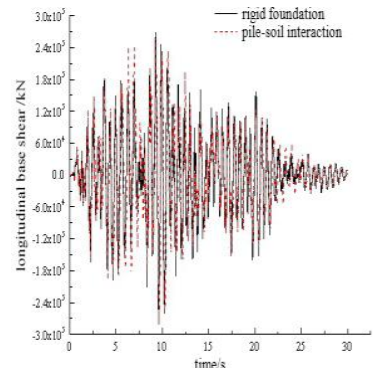

(a)

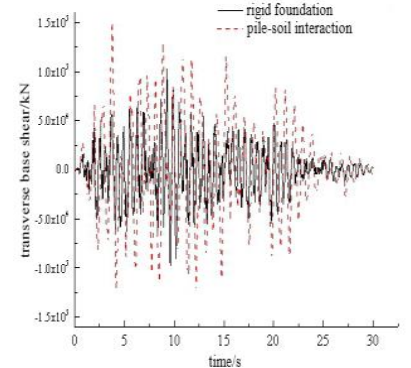

(b)

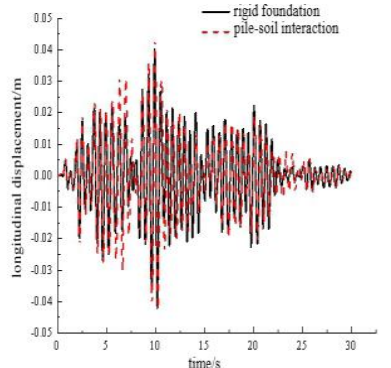

(c)

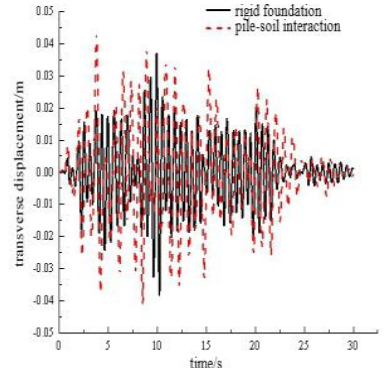

(d)

Figure6.The time history curves of the base shear and the displacement

\section{Conclusions}

Based on the actual project, we use the finite element software MIDAS/GEN to establish the integrated station-bridge structure model and analyze its dynamic response under the rigid foundation action and pile-soil interaction. Through the comparison of the two results, we analyzed the influence of pile-soil interaction on the dynamic response of the structure. Thus the following conclusions can be drawn:

(1) Compared with the rigid foundation, the pile-soil interaction makes the structure period longer and the rigidity smaller. Whether or not there is pile-soil interaction, the low order mode of the two structures is basically the same, and the the first-order mode is mainly transverse translation.

(2) Compared with the rigid foundation, under frequently occurred earthquake action, the pile-soil interaction reduces the base shear and increases the maximum story drift.The rigid foundation under frequently occurred earthquake action makes the result more conservative.

(3) Compared with the rigid foundation, under seldomly occurred earthquake action, the pile-soil interaction increases the base shear and top floor displacement, and the transverse increase is significantly greater than the longitudinal increase. Based on the rigid foundation, the time history analysis results are smaller under the seldomly occurred earthquake action. Therefore, when analyzing the dynamic response, the influence of pile-soil interaction on the structure cannot be ignored.

\section{References}

1. LI Shuai, DENG Tongfa, CHEN Lei. Analysis of seismic response of curved bridge with pile-soil interaction[J]. Journal of jiangxi university of science and technology, 2008,39(01):27-31.

2. LUO Guoqing, ZHENG Kaifeng. Impact of pile and soil action on continuous steel box girder bridge structure $\quad[\mathrm{J}]$. Guangdong highway traffic,2008(03):12-14+26.

3. SHENG Ping, WANG Yi, ZHANG Nan. Study of vibration comfort of a bridge-station combined railway station[J]. Architectural structure, 2009,39(12):43-45+58.
4. ZHENG Jian. The applications of spatial structures in large railway stations [J]. Space structure, 2009, 15(03):52-65.

5. GB50011-2010. Code for seismic design of buildings [S]. Beijing: China building industry press, 2010 .

6. GB50111-2006. Code for seismic design of railway engineering [S]. Beijing: China railway publishing house, 2009.

7. DONG Cheng, LI Zhongxian. Structural Design and Seismic Analysis of Integral Station-Bridge Structure in Light Railway [J]. Journal of fuzhou university (natural science edition), 2005(S1): 192-196.

8. WANG Yi, ZHANG Li. Study on seismic behavior of large bridge-station combined railway station[J]. Building structure, 2009, 39(12): 23-27.

9. MYLONAKIS G, GAZETAS G, Seismic soil-structure interaction: beneficial or detrimental[J] Journal of Earthquake Engineering.2000, 4(3): 277-301.

10. CARBONARI S, DEZI F, LEONI G, Seismic soil-structure interaction in multi-span bridges: application to a railway bridge[J]. Earthquake Engineering and Structual Dynamics, 2011, 40(11): 1219-1239.

11. WANG Fengxia, HE Zheng, OU Jinping.The elastic seismic response analysis of pile-soil-structure interaction system[J]. World earthquake engineering,2003(02):58-66.

12. TB10093-2017. Code for design of railway bridge and culturefoundation and foundation [S]. Beijing: China railway publishing house, 2017.

13. FU Tao. IDA-Based Seismic Performance Evaluation of Small Integrated Station-Bridge Structure in High speed Rail[D]. Beijing jiaotong university, 2015.

14. ASCE Minimum design loads for buildings and other sturtures[s]. Reston: American Society of civil Engineers, 2005.

15. WEN Lingyan, LOU Yu, NIE Jianguo. Energy-based analysis in elastic-plastic time-history analysis of structure under large earthquake[J]. Journal of civil engineering, 2014, 47(05): 1-8. 